morbidity than hypokalaemia in patients on long-term diuretic treatment.

The help of the staff of the department of chemical pathology and the co-operation of our clinical colleagues are much appreciated.

\author{
References \\ ${ }^{1}$ Bartter, F C, and Schwartz, W B, American fournal of Medicine, 1967, 42, \\ 790 \\ 2 de Troyer, A, and Domenet, J C, Quarterly fournal of Medicine, 1976, 45, \\ 521
}

3 Thomas, T H, et al, Lancet, 1978, 1, 621.

${ }^{4}$ Fichman, M P, et al, Annals of Internal Medicine, 1971, 75, 853.

${ }^{5}$ Swales, J D, Sodium Metabolism in Disease, p 66. London, Lloyd-Luke, 1975.

${ }^{6}$ Arieff, A I, et al, Medicine, 1976, 55, 121.

' Bisset, G W, and Jones, N F, in Recent Advances in Renal Disease I, ed N F Jones, p 398. Edinburgh, Churchill-Livingstone, 1975.

${ }^{8}$ Deutsch, R R, et al, Anesthesiology, 1966, 27, 250.

${ }^{9}$ Swales, J D, Sodium Metabolism in Disease, p 67. London, Lloyd-Luke, 1975 .

${ }^{10}$ Blythe, W B, et al, American fournal of Physiology, 1968, 214, 52.

\title{
Evidence for a primary autoimmune type of diabetes mellitus
}

\author{
G F BOtTAZZO, A G CUDWORTH, D J MOUL, D DONIACH, H FESTENSTEIN
}

British Medical fournal, 1978, 2, 1253-1255

\section{Summary and conclusions}

Sixty-eight patients with longstanding diabetes and persistent islet-cell antibody and 35 with coexistent diabetes and Graves's disease or primary myxoedema were studied with particular reference to the HLA system and autoantibody patterns. A higher incidence of HLA-B8 than normal was observed in the two groups. An additive relative risk exists when type $I$ diabetes and autoimmune thyroid disease coexist, indicating that different HLA-linked genes may confer susceptibility to the pancreatic and thyroid disorders. Other characteristics, including female predominance, a later onset of diabetes, and a strong family history of autoimmune endocrinopathy, provide further evidence that this form of diabetes is aetiologically distinct from that generally seen in children.

These results support the hypothesis of a primary autoimmune type of diabetes mellitus.

\section{Introduction}

Much interest has been focused on the biological importance of the underlying genetic determination and associated autoimmune phenomena in insulin-dependent diabetes irrespective of the age of onset (type I diabetes ${ }^{2}$ ). There is a significant positive association between HLA-B8 and several organ-specific autoimmune disorders including Graves's disease, Addison's disease, and myasthenia gravis. ${ }^{3}$ HLA-B8 is also associated with type I diabetes, but there is interesting evidence of a more complex relation in this disease, with a double axis of HLA

\footnotetext{
Department of Immunology, Middlesex Hospital Medical School, London W1P 7PN

G F BOTTAZZO, MD, lecturer in clinical immunology

D DONIACH, .MD, FRCP, emeritus professor of clinical immunology

Medical Unit, St Bartholomew's Hospital, London EC1A 7BE

A G CUDWORTH, MD, FRCP, consultant physician and senior lecturer D J MOUL, MRCP, senior registrar

H FESTENSTEIN, DIPBACT, FRCPATH, professor of immunology
}

determinants conferring susceptibility and a single axis conferring protection. ${ }^{1+}$ In people positive for HLA-B8 the relative risk of developing either diabetes or Graves's disease is increased two to three times. ${ }^{13}$ No studies of primary myxoedema have been reported, and the association between Hashimoto's disease and the HLA system is still controversial. ${ }^{5} 6$

The increased prevalence of thyrogastric antibodies in patients with insulin-dependent diabetes is well recognised.? Islet-cell antibodies (ICA) are prominent and persistent in patients with polyendocrine disease and are found more transiently in children with uncomplicated diabetes. ${ }^{8}{ }^{9}$ Accordingly it has been suggested that pancreatic antibodies might be used as a marker for subdividing type I diabetes into two syndromes of different aetiology-namely, "juvenile" diabetes (type Ia), in which the autoimmune marker may occur in response to hypothetical viruses, and "primary autoimmune" or "polyendocrine" diabetes (type Ib). ${ }^{10}$ Results of a recent study in children has supported this dual hypothesis, since ICA persisting for more than three years were strongly associated with the presence of other organ-specific antibodies in the patients and their families. ${ }^{11}$

An important question is whether the same or separate genes in linkage disequilibrium with HLA-B8 confer susceptibility to diseases in different endocrine organs. In order to elucidate this further we studied longstanding diabetics, some of whom had coexistent primary thyroid disease.

\section{Patients and methods}

We studied two groups of patients as follows:

Group 1-This group comprised 68 longstanding diabetics (mean duration of diabetes 19.5 years) with persistent ICA, whom we investigated with particular reference to clinical characteristics and other immunological features. Sixty-one patients were insulin dependent, and seven had been receiving diet and treatment by mouth for a considerable time (14-39 years). Thirty-nine of the insulindependent group who had no clinical or biochemical evidence of other autoimmune endocrinopathy were HLA-typed.

Group 2-This group comprised 35 patients with coexistent type I diabetes and thyroid disease. All were receiving insulin. Eighteen patients had presented with classical features of Graves's disease. The diagnosis of primary myxoedema in 17 patients was made on clinical and metabolic features; none of these patients had previously been thyrotoxic or had a palpable goitre suggestive of Hashimoto's disease.

Methods-We carried out HLA-A and B typing for 34 specificities using a standard microlymphocytotoxicity method. ${ }^{12}$ Relative risks were computed by the Woolf method ${ }^{13}$ as modified by Haldane. ${ }^{14}$ 
The probabilities estimated for comparing patients and controls were twice the value of $\mathrm{P}, \mathrm{P}$ being derived by the Fisher-Irwin exact test. The controls comprised 561 healthy Caucasian subjects. The results were also compared with those from 288 previously reported cases of type I diabetes alone ${ }^{15}$ and 54 patients with Graves's disease alone, ${ }^{16}$ all of whom had been HLA-typed. All patients' sera were tested fresh or after storage at $-20^{\circ} \mathrm{C}$. Immunofluorescence tests were performed using a standard sandwich technique with undiluted sera. ICA were detected on fresh postmortem blood group $\mathrm{O}$ human pancreas as previously described. ${ }^{2}$ Gastric parietal cell and adrenal antibodies were also detected on human organ tissue. Thyroglobulin and thyroid microsomal antibody titres were estimated with commercial haemagglutination kits (Wellcome Reagents Ltd) of formalinised red blood cells coated with human thyroglobulin and thyroid microsomes respectively. The lowest titres regarded as positive were $1 / 20$ and $1 / 100$ respectively. When present, non-organ-specific antibodies such as mitochondrial, smooth muscle, and nuclear antibodies were seen on the combined tissue sections.

\section{Results}

Forty-four $(65 \%)$ of the longstanding diabetics with persistent ICA (group 1) were female. The age of onset of diabetes varied widely (2-70 years), although for most patients it was later (mean 29 years) than is generally seen in classical "juvenile-type" diabetes. Organ-specific autoantibodies were investigated in 60 patients. Thirty-nine $(65 \%)$ had thyroid or gastric antibodies, and in addition six $(10 \%)$ had adrenal antibodies, which are usually extremely uncommon in the absence of Addison's disease. Five patients had overt clinical myxoedema. Thyroid function tests were carried out in the remainder, only one of whom was found to have biochemical hypothyroidism.

Table I compares the incidences of certain HLA antigens in the 39 patients with persistent ICA and no evidence of other autoimmune endocrine disease with the incidences in patients with type I diabetes of similar duration without ICA. There was a significantly increased incidence of $\mathrm{B} 8$ in those with persistent ICA $(P=0.03$; relative risk $=$ $2 \cdot 25$ ). Interestingly, there was also a significant increase in the proportion of patients with two high-risk antigens (for example, B8 and B15), one from each axis of HLA factors observed in type I diabetes.

TABLE I-Incidences of various HLA antigens in type $I$ diabetics with and without islet-cell antibodies for over five years

\begin{tabular}{|c|c|c|c|c|}
\hline $\begin{array}{c}\text { HLA } \\
\text { antigen }\end{array}$ & $\begin{array}{l}\text { No }\left({ }^{\circ}{ }_{0}\right) \text { of } \\
\text { patients } \\
\text { with ICA } \\
(\mathrm{n}=39)\end{array}$ & $\begin{array}{c}\text { No }\left({ }^{\prime}{ }_{0}\right) \text { of } \\
\text { patients } \\
\text { without ICA } \\
(\mathrm{n}=115)\end{array}$ & $P$ value & $\begin{array}{c}\text { Relative } \\
\text { risk }\end{array}$ \\
\hline $\begin{array}{c}\text { A1 } \\
\text { B7 } \\
\text { B8 } \\
\text { B15 } \\
\text { B18 } \\
\text { B40 } \\
\text { B8 and B15 } \\
\text { B8 and B40 }\end{array}$ & $\begin{array}{r}21(53 \cdot 8) \\
5(12 \cdot 8) \\
27(69 \cdot 2) \\
7(17 \cdot 9) \\
5(12 \cdot 8) \\
11(28 \cdot 2) \\
7(17 \cdot 9) \\
6(15 \cdot 4)\end{array}$ & $\begin{array}{c}51(44 \cdot 3) \\
13(11 \cdot 3) \\
57(49 \cdot 6) \\
20(17 \cdot 4) \\
11(9 \cdot 6) \\
14(12 \cdot 2) \\
7(6 \cdot 1) \\
3(2 \cdot 6)\end{array}$ & $\begin{array}{r}\text { NS } \\
\text { NS } \\
0.03 \\
\text { NS } \\
\text { NS } \\
0.03 \\
0.05 \\
0.01\end{array}$ & $\begin{array}{l}1.45 \\
1.21 \\
2.25 \\
1.07 \\
1.38 \\
2.75 \\
3.21 \\
6.17\end{array}$ \\
\hline
\end{tabular}

NS $=$ Not significant .

Twenty-eight $\left(80_{0}^{\circ}\right)$ of the 35 patients in group 2 were female. The mean age of onset of diabetes was $35 \cdot 6 \pm$ SD $17 \cdot 4$ years in the 18 patients with coexistent Graves's disease and $40 \cdot 8 \pm 17 \cdot 7$ years in the 17 with associated primary myxoedema. Only five patients in the whole series developed diabetes before the age of 20 . In contrast the mean age of onset of the thyroid disorder was compatible with that expected in the absence of diabetes. Eight and 10 patients respectively had diabetes before clinical hyper- or hypothyroidism developed. In 11 patients the two diseases occurred simultaneously or within one year of each other. An additional autoimmune disorder was present in nine patients. In those with myxoedema pernicious anaemia was the most common association $(n=4)$, though there was also one case of myasthenia gravis and one of rheumatoid arthritis. A case of Addison's disease and one of vitiligo also occurred, one in each group.

A strong family history of autoimmune disease was observed. Twothirds of all patients had one or more relatives with an autoimmune disorder, and eight of the nine patients with additional diseases had affected relatives. Of all the patients, $41(40 \%)$ had family histories of diabetes and $35\left(34_{\%}^{\circ}\right)$ of thyroid disease; 14 had relatives in whom the pancreas and thyroid were affected. In addition four families had associated pernicious anaemia, coeliac disease, and rheumatoid arthritis. The two groups showed similar numbers of affected relatives-namely, one to three per family.

With respect to group 2, table II shows the frequency distributions, relative risks, and probability values for those HLA antigens known to have a significant positive or negative association with either type I diabetes or Graves's disease. Sixteen $\left(89^{\circ}\right)$ of patients with diabetes and Graves's disease, and $13(77 \%)$ of patients with diabetes and primary myxoedema were positive for HLA-B8. Seven patients $\left(20^{\circ}\right)$ had two high-risk HLA-B antigens for diabetes-that is, B8 and B15 or B8 and B40. Five of these patients had diabetes with Graves's disease. The increase in Al was attributable to linkage disequilibrium between $\mathrm{A} 1$ and B8, as observed previously. ${ }^{1}$ There was no significant disturbance in the incidence of any of the other HLA alleles known to be associated with type 1 diabetes (for example, $\mathrm{B} 15, \mathrm{~B} 18)$. There was a low relative risk associated with $\mathrm{B} 7(0.57)$, but this was not significant. In patients positive for HLA-B8 the relative risk for having both diabetes and thyroid disease was about four to seven times that seen in each condition analysed separately (table III).

We investigated 30 patients for ICA, and 28 for thyroid, gastric parietal, and adrenal antibodies (table IV). The overall incidence of ICA was $53 \%$, with a higher incidence in patients with diabetes and Graves's disease $\left(64^{\circ}\right)$ than in those with diabetes and primary myxoedema $\left(44^{\circ}{ }_{0}\right)$. The mean duration of diabetes in the ICApositive patients was $18.1+11.3$ years and was similar in the two groups. All patients with persistent ICA had evidence of other organspecific autoimmunity, and $12\left(75^{\circ}\right)$ were positive for HLA-B8. As expected, most of the patients had thyroid antibodies. In the thyrotoxic group thyroid microsomal antibodies were present in a much higher proportion of cases than is usual for uncomplicated thyrotoxicosisnamely, in $93^{\circ}{ }^{\circ}$ as compared with $70^{\circ}$, ; in the myxoedema group the incidence was lower $\left(71^{\circ}{ }_{0}\right)$, possibly due to the long duration of the

TABLE II-Incidences of HLA antigens in 35 patients with coexistent type I diabetes and thyroid disease

\begin{tabular}{c|c|c|c|c}
\hline $\begin{array}{c}\text { HLA } \\
\text { antigen }\end{array}$ & $\begin{array}{c}\text { No }\left(0^{\prime \prime}\right) \text { of } \\
\text { patients } \\
\text { positive }\end{array}$ & $\%^{2}$ & $\begin{array}{c}\text { Relative } \\
\text { risk }\end{array}$ & P value \\
\hline A1 & $26(74.3)$ & 23.06 & 5.71 & $1.43 \times 10^{-6}$ \\
B7 & $5(14.3)$ & 1.25 & 0.57 & NS \\
B8 & $29(82.9)$ & 54.37 & 13.62 & $6.56 \times 10^{-12}$ \\
B15 & $5(14.3)$ & 0.03 & 1.03 & NS \\
B18 & $4(11.4)$ & 1.28 & 2.49 & NS \\
B40 & $4(11.4)$ & 0.04 & 1.14 & NS \\
B8 and B15 or & $7(20.0)$ & 21.96 & 10.15 & $1.19 \times 10^{4}$ \\
B8 and B40 & $7(20)$ & & & \\
\hline
\end{tabular}

$\chi^{2}$ values obtained by Yates's method; relative risks by that of Haldane. ${ }^{14}$
SS $=$ Not significant.

TABLE III-Relative risk in patients positive for $H L A-B 8$ with type I diabetes mellitus (DM) and autoimmune thyroid disease compared with that in patients with type I diabetes or Graves's disease alone

\begin{tabular}{|c|c|c|c|c|}
\hline & $\begin{array}{l}\text { Type I DM } \\
\text { and Graves's } \\
\text { disease or } \\
\text { primary } \\
\text { myxoedema } \\
(\mathrm{n}=35)\end{array}$ & $\begin{array}{c}\text { Type I DM } \\
\text { alone } \\
(\mathrm{n}=288)^{15}\end{array}$ & $\begin{array}{l}\text { Type I DM } \\
\text { and Graves's } \\
\text { disease } \\
(\mathrm{n}=18)\end{array}$ & $\begin{array}{l}\text { Graves's } \\
\text { disease alone } \\
(\mathrm{n}=54)^{16}\end{array}$ \\
\hline $\begin{array}{l}\text { No }(\circ) \text { positive } \\
\text { for HLA-B8 } \\
\%^{2} \text { value } \\
\text { Relative risk }\end{array}$ & \multicolumn{2}{|c|}{$\begin{array}{c}29(82 \cdot 9) \quad 148(51 \cdot 4) \\
11 \cdot 24 \\
2 \cdot 47 \times 10 \\
4.29\end{array}$} & \multicolumn{2}{|c|}{$\begin{array}{c}16(88 \cdot 9) \quad 27(50 \cdot 0) \\
7 \cdot 311^{-34} \times 10^{-3} \\
6 \cdot 84\end{array}$} \\
\hline
\end{tabular}

TABLE IV-Incidence of organ-specific autoantibodies

\begin{tabular}{|c|c|c|c|c|}
\hline & Islet-cell & $\begin{array}{l}\text { Thyroid } \\
\text { microsomal }\end{array}$ & $\begin{array}{l}\text { Gastric } \\
\text { parietal }\end{array}$ & Adrenal \\
\hline $\begin{array}{l}\text { Paticnts with DM plus } \\
\text { Graves's disease } \\
\text { Patients with DM plus }\end{array}$ & $9 / 14\left(64^{\circ}\right)$ & $13 / 14\left(93^{\circ}{ }_{10}\right)$ & $7 / 14\left(50_{11}^{\circ}\right)^{*}$ & $1 / 14(7 \%)+$ \\
\hline primary myxoedema & $7 / 16(44 \%)$ & $10.14\left(71_{0}^{\circ}\right)$ & $8 / 14\left(57_{0}^{0}\right)_{+}^{+}$ & $1 / 14\left(7_{\circ}^{\circ}\right)^{*}$ \\
\hline
\end{tabular}

$\mathrm{DM}=$ Diabetes mellitus.
${ }^{*}$ None had pernicious anaemia. $\quad$ Known to have Addison's disease. $\quad$ Three had pernicious anaemia (two could not be tested). 
thyroiditis. Thyroglobulin antibodies were less conspicuous and were present in low titres in five patients and in high titre in one with myxoedema.

Gastric parietal cell antibodies were found in $53.5 \%$ of the patients compared with $30^{\circ}$ o of subjects with uncomplicated thyroid disorders. Adrenal antibodies were detected in only the two patients with Addison's disease. No antinuclear or other non-organ-specific antibodies were seen in this series.

\section{Discussion}

Diabetes mellitus is now accepted to be a syndrome rather than a single disease. The broad division into types I and IIthat is, insulin-dependent and insulin-independent diabetes, irrespective of age of onset-is now widely recognised. Genetic and immunological studies have indicated the possibility of heterogeneity, which implies that different pathological mechanisms participate in the destruction of the beta cells in the pancreatic islets. There is a strong familial aggregation of primary autoimmune endocrinopathies, which suggests that several genes might be implicated in the genetic predisposition to the polyendocrine diathesis. To reinforce this concept there are additional common clinical and serological features that are recognised in defining a primary autoimmune endocrine disease - for example, female predominance, tendency to adult onset, and chronicity of the pathological processes. Lifelong autoimmunisation is also characteristic of thyroiditis, gastritis, and adrenalitis. All these features occurred in this study in patients with type I diabetes and overt coexistent thyroid disease, and also in diabetics with persistent ICA without other overt disease. This last fact probably indicates a state of potential polyendocrinopathy.

The additive relative risk (four- to sevenfold) in respect of HLA-B8 observed in patients with type I diabetes and thyroid disease strongly suggests that different genes are in linkage disequilibrium with the HLA-B8 locus conferring susceptibility to these pathological processes.

The tendency to autoimmunity may also be seen quantitatively. We found nearly twice as much gastric autoimmunity in the diabetics than occurs in patients with either thyroiditis or diabetes alone. On the other hand, pernicious anaemia was more often associated with myxoedema than with thyrotoxicosis, even though there is an equal prevalence of intrinsic factor antibodies in the two conditions. ${ }^{1-}$

We found a strong association between HLA-B8 and primary myxoedema. This suggests an analogy with results of a study of pernicious anaemia ${ }^{1}$ in which a significant relative risk with B8 emerged only in cases associated with diabetes or thyroid disease. A similar observation might be relevant for Hashimoto's thyroiditis if patients are selected with coexistent autoimmune e docrinopathy.

The results of these studies support the present hypothesis concerning the pathogenesis of type I diabetes. Thus, whereas diabetics with other endocrinopathy are uncommon and probably account for under $10^{\circ}$ of insulin-dependent patients, they appear to form a well-differentiated subgroup characterised clinically or serologically, or both, by the classical manifestations of primary autoimmune endocrine disease.

An important question is whether diabetics with persistent ICA have a similar primary autoimmune beta-cell destruction. Evidence in favour of this is provided by the stronger association with HLA-B8 in patients with persistent ICA compared with those negative for ICA; the clinical characteristics mentioned above; and the higher prevalence of other organ-specific autoantibodies in the same patients and their close relatives. In contrast, in the typical "juvenile-type" diabetic (type Ia) there is a slight male predominance, a generally earlier age of onset (11-13 years), and constant seasonal variation. ${ }^{19}$ This type of disease is characterised by an association with several different HLA factors including B8 and B15, with temporary pancreatic autoimmunity, and a weak correlation with thyrogastric antibodies.

Thus further study of the unusual polyendocrine autoimmune syndromes will probably yield more information about the pathogenesis of these diseases.

We are grateful to Professor Michael Besser for allowing us to study patients under his care, and to Professor Ivan Roitt for his continued support. We thank Mrs B Dean, Miss M O'Kane, Miss M Shattock, and Miss B Watson for their skilled technical help. Miss B Watson was supported by the Joint Research Board of St Bartholomew's Hospital.

This work was supported by the British Diabetic Association and the Medical Research Council.

\section{References}

1 Cudworth, A G, Diabetologia, 1978, 14, 281.

2 Doniach, D, and Bottazzo, G F, Pathobiology Annual, 1977, 7, 327.

${ }^{3}$ Nerup, J, et al, HLA and Disease, ed J Dausset and A Svejgaard, p 155. Copenhagen, Munksgaard, 1977.

${ }^{4}$ Cudworth, A G, and Festenstein, H, British Medical Bulletin, 1978, 34, 285.

5 Volpe, R, Clinics in Endocrinology and Metabolism, 1978, 7, 3.

${ }^{6}$ Brown, J, et al, Annals of Internal Medicine, 1978, 88, 379.

' Irvine, W J, et al, Lancet, 1970, 2, 163.

${ }^{8}$ Lendrum, R, et al, Lancet, 1976, 2, 1273.

${ }^{9}$ Irvine, W J, et al, Diabetes, 1977, 26, 138

10 Bottazzo, G F, and Doniach, D, Lancet, 1976, 2, 800.

11 Bottazzo, G F, et al, British Medical fournal, 1978, 2, 165.

12 Terasaki, P I, and McClelland, J D, Nature, 1964, 204, 998

13 Woolf, B, Annals of Human Genetics, 1955, 19, 251.

14 Haldane, J B S, Annals of Human Genetics, 1956, 20, 309.

${ }^{15}$ Cudworth, A G, and Woodrow, J C, British Medical fournal, 1976, 2, 846.

${ }^{16}$ Cudworth, A G, unpublished observations.

17 Rose, M S, et al, Lancet, 1970, 2, 9.

18 Ungar, B, et al, British Medical fournal, 1977, 1, 798.

19 Gamble, D R, in The Genetics of Diabetes Mellitus, ed W Creutzfeldt, J Köbberling, and J V Neal, p 95. Berlin, Springer-Verlag, 1976.

(Accepted 4 September 1978)
ONE HUNDRED YEARS AGO Mr J J Coleman, having lately been a sufferer from a serious illness, a prominent symptom of which was inability to digest food, was ordered to take a malt extract. The usual dose-a wine-glassful twice or thrice a day-was taken with the result that food, which had hitherto escaped undigested, was assimilated, and the power of producing animal heat and storing up fat was increased. Other persons-thin, cold, or aged-were induced to become the subjects of experiment, and reported that it was far more sustaining than most alcoholic liquors. These facts led $\mathrm{Mr}$ Coleman to make an extended series of experiments, which he has embodied in a paper read before the Glasgow Philosophical Society, and which is abstracted in the Chemist and Druggist of May 15th. Analysis of the extract proved that, in composition, it closely resembled other malt liquors, differing chiefly by yielding a rather larger percentage of extract. In appearance, it resembles porter. An explanation of the sensation of being lifted from a feeling of semi-starvation to the condition of being effectually warmed and nourished, seemed to be required. The four per cent of alcohol in the extract, and other malt liquors, could not explain its permanent heating effects. The scientific experiments of Drs Richardson and Edward Smith prove that an equal quantity of sugar has a more permanent power of warming, and popular experience confirms their statements. Now, the diastase contained in malt is able to convert the starch of four or five times its weight of barley into soluble substances. Starch forms a very large proportion of our daily food, and it seemed possible that, by rendering this more soluble, Hoff's malt extract might produce the effects which had been experienced. Experiments were, therefore, instituted to decide the question; and it was conclusively proved that all malt liquors exert a more or less powerful solvent action on bread and other starchy foods, and that Hoff's liquid possesses four times the power of Burton ale, and half as much again as London porter. This action is so great as fully to account for the good effects observed to follow their use. (British Medical fournal, 1878.) 